Research Paper

\title{
Impact of prostatic anterior fat pads with lymph node staging in prostate cancer
}

\author{
Wei-Chun Weng1,2,3, Li-Hua Huang1, Chao-Yu Hsu', Min-Che Tung1, Cheng-Kuang Yang", Jong-Shiaw \\ $\mathrm{Jin}^{5}$, Yen-Chuan $\mathrm{Ou}^{1,}{ }^{\circledR}$, Shun-Fa Yang ${ }^{2,6,}$, \\ 1. Division of Urology, Department of Surgery, Tungs' Taichung MetroHarbor Hospital, Taichung, Taiwan \\ 2. Institute of Medicine, Chung Shan Medical University, Taichung, Taiwan \\ 3. Department of Nursing, Jen-Teh Junior College of Medicine, Nursing and Management, Miaoli, Taiwan \\ 4. Division of Urology, Department of Surgery, Taichung Veterans General Hospital, Taichung, Taiwan \\ 5. Department of Pathology, Tungs' Taichung MetroHarbor Hospital, Taichung, Taiwan \\ 6. Department of Medical Research, Chung Shan Medical University Hospital, Taichung, Taiwan \\ $\square$ Corresponding authors: Shun-Fa Yang, Ph.D. or Yen-Chuan Ou, M.D., Ph.D., Institute of Medicine, Chung Shan Medical University, Taichung 402, Taiwan; \\ Tel: +886-4-24739595 ext. 34253; Fax: +886-4-24723229; E-mail: ysf@csmu.edu.tw (Shun-Fa Yang); ycou228@gmail.com (Yen-Chuan Ou) \\ (c) Ivyspring International Publisher. This is an open access article distributed under the terms of the Creative Commons Attribution (CC BY-NC) license \\ (https://creativecommons.org/licenses/by-nc/4.0/). See http://ivyspring.com/terms for full terms and conditions.
}

Received: 2018.02.14; Accepted: 2018.07.17; Published: 2018.09.08

\begin{abstract}
Background: Several reports have revealed the presence of lymph nodes in the prostatic anterior fat pad (PAFP). To date, no study has described the characteristics of Taiwanese patients harboring PAFP lymph nodes with metastatic prostate cancer involvement.

Method: Between December 2006 and May 2015, a total of 849 consecutive patients underwent robot-assisted laparoscopic radical prostatectomy with PAFP dissection. Pathological examination of the dissected PAFP was conducted to assess the presence of lymphoid tissue and prostate cancer involvement.

Results: Of the 849 patients, 76 (9.0\%) had 1-3 PAFP lymph nodes. Moreover, 11 (1.3\%) of the 76 patients had positive lymph node metastases of prostate cancer in the PAFP; $5(0.6 \%)$ of the 11 patients, who had negative pelvic lymph node involvement, were upstaged because of positive metastases in PAFP lymph nodes. Among the 76 patients having PAFP lymph nodes, metastatic lymph nodes were associated with the clinical T stage, preoperative Gleason score, pathological T stage, and pathological $N$ stage $(\mathrm{p}<0.001)$. Patients with pathological seminal vesicle invasion and a higher surgical Gleason score also exhibited PAFP lymph node metastases $(p<0.005)$.

Conclusion: Our data show that $9.0 \%$ of patients had PAFP lymph nodes and that $1.3 \%$ had prostate cancer metastases. Additionally, $0.6 \%$ of patients were upstaged because of positive metastases in PAFP lymph nodes. Because of the pathological analysis of the PAFP, a few patients were upstaged. Thus, routine pathological analysis of the PAFP should only be conducted for those with higher preoperative prostate-specific antigen, higher Gleason score, and advanced $\mathrm{T}$ stage observations.
\end{abstract}

Key words: Lymph nodes, prostatic anterior fat pad, prostate cancer

\section{Introduction}

Pelvic lymph node dissection (PLND) is the most common method for nodal staging in prostate cancer patients undergoing radical prostatectomy (RP) [1-3]. PLND provides valuable information about the starting time of adjuvant radiotherapy and androgen deprivation therapy and may have a therapeutic benefit in prostate cancer patients [3, 4]. Some series have shown high cancer-specific survival rates for patients with only one or two lymph node metastases after extended lymphadenectomy [5, 6].

The prostatic anterior fat pad (PAFP) refers to the adipose tissue anterior to the prostate. PAFP 
excision is recommended in patients treated with $\mathrm{RP}$ to aid in the identification of the prostatic apex, dorsal venous complex, and bladder neck [7, 8]. Several series have reported the presence of PAFP lymph nodes, some of which had metastatic prostate cancer involvement, resulting in disease upstaging in patients with negative pelvic node involvement [8-16]. Manny et al. [17] injected indocyanine green (ICG) into the prostate before RP and could detect lymphatic drainage in the PAFP. In our hospital, since 2006, the PAFP has been routinely removed during robot-assisted laparoscopic radical prostatectomy (RALRP) for more effective anatomical identification, with the dissected PAFP being sent for separate pathological analysis. Based on these data, in this study, we analyzed the rate of the presence of PAFP lymph nodes and the risk factors for PAFP lymph nodes metastases.

\section{Materials and Methods}

\section{Patients}

This study was approved by the Institutional Review Boards of Taichung Veterans General Hospital (TCVGH) and Tungs' Taichung MetroHarbor Hospital (TTMHH). Moreover, this study was exempted from obtaining informed consent because of its retrospective design. In this study, only men with prostate cancer who underwent RALRP with PAFP excision and PLND during the same operation from December 2006 to May 2015 were included. Patients undergoing conventional prostate surgery and laparoscopic prostate surgery were excluded. A total of 849 consecutive prostate cancer patients undergoing RALRP performed by a single surgeon at the two hospitals met the criteria. The preoperative diagnosis of prostate cancer was based on transrectal prostate biopsy or transurethral prostate resection. Patients were initially diagnosed at TCVGH or TTMHH or were referrals from other hospitals. The pathological grading of the transrectal prostate biopsy sample was conducted using the Gleason grading system. Cancer with clinical $\mathrm{T}$ stages from T1 to T3 was categorized as localized prostate cancer. The presence of nodal or bony metastasis was detected by preoperative image surveys such as computed tomography, magnetic resonance imaging, or technetium-99m bone scan. Preoperative work-up included measuring the prostate-specific antigen (PSA) level and assessing the clinical stage assigned by attending urologists. The pretreatment PSA level was measured before digital rectal examination and transrectal ultrasound. Moreover, PAFP dissection was performed in a caudal-cranial direction to the bladder neck. The boundaries of PAFP dissection were caudate to the prostate apex, superiorly to the pubic arch, inferiorly to the prostate, laterally to the edges of the prostate joining the endopelvic fascia, and cephalad to the bladder neck. All patients underwent PAFP excision before prostatectomy and bilateral PLND. For pathological analysis, PAFP, right PLND, and left PLND were placed in three separate containers.

\section{Statistical Analysis}

Data analysis was performed using the statistical analysis system (SAS). A two-sided Student's $t$ test was used to determine the differences in continuous data, and a chi-squared test or Fisher exact test were used to compare differences in categorical data.

\section{Results}

The PAFP tissue of 849 patients was analyzed pathologically. Of the 849 patients, $76(9.0 \%)$ had 1 to 3 lymph nodes in their PAFP. Moreover, 63 patients had only 1 lymph node, 10 patients had 2 lymph nodes, and 3 patients had 3 lymph nodes, with an average of 1.2 nodes per patient. Metastatic prostate cancer was detected in PAFP lymph nodes in 11 patients $(1.3 \%)$.

The preoperative characteristics of patients with and without lymph nodes in the PAFP are shown in Table 1. Patients with PAFP lymph nodes tended to have a higher clinical T stage $(\mathrm{p}<0.05)$. No differences were observed in patients' age, body mass index, prostate weight, PSA, or preoperative Gleason score.

Table 1. Demographics comparing patients with lymph nodes present or absent in prostatic anterior fat pad (PAFP).

\begin{tabular}{llll}
\hline Variable & $\begin{array}{l}\text { Lymph nodes absent } \\
\text { in PAFP }(\mathrm{n}=773)\end{array}$ & $\begin{array}{l}\text { Lymph nodes } \\
\text { present in PAFP } \\
(\mathrm{n}=76)\end{array}$ & p value \\
\hline $\begin{array}{l}\text { Age at surgery, Mean } \pm \\
\text { SD }\end{array}$ & $65.71 \pm 7.73$ & $66.76 \pm 7.88$ & 0.256 \\
BMI, Mean \pm SD & $24.76 \pm 3.03$ & $24.98 \pm 3.14$ & 0.549 \\
Prostate weight, Mean & $41.57 \pm 19.25$ & $45.54 \pm 21.82$ & 0.103 \\
\pm SD & & & \\
PSA, $n(\%)$ & $339(43.9 \%)$ & $36(47.4 \%)$ & 0.069 \\
$0-10$ & $255(33.0 \%)$ & $16(21.1 \%)$ & \\
$10-20$ & $179(23.1 \%)$ & $24(31.6 \%)$ & \\
$>20$ & & & 0.093 \\
Preoperative Gleason & & $34(44.7 \%)$ & \\
Score, $n(\%)$ & $375(48.5 \%)$ & $20(26.3 \%)$ & \\
$2-6$ & $253(32.7 \%)$ & $22(29.0 \%)$ & \\
7 & $145(18.8 \%)$ & & \\
$8-10$ & & $19(25.0 \%)$ & \\
Clinical T stage, $n(\%)$ & $239(30.9 \%)$ & $17(22.4 \%)$ & \\
T1abc & $249(32.2 \%)$ & $23(30.3 \%)$ & \\
T2/T2a/T2b & $214(27.7 \%)$ & $17(22.4 \%)$ & \\
T2c & $71(9.2 \%)$ & & \\
T3 & & & \\
\hline
\end{tabular}

Table 2 lists the surgical and pathological data of the two groups. The presence of PAFP lymph nodes was related to more aggressive prostate cancer with seminal vesicle invasion and a higher Gleason score. 
Moreover, metastatic prostate cancer in pelvic lymph nodes showed a strong association with the presence of PAFP lymph nodes ( $\mathrm{p}<0.001)$.

Table 2. Surgical and pathologic data comparing patients with lymph nodes present or absent in prostatic anterior fat pad (PAFP).

\begin{tabular}{llll}
\hline Variable & $\begin{array}{l}\text { Lymph nodes } \\
\text { absent in PAFP } \\
(\mathrm{n}=773)\end{array}$ & $\begin{array}{l}\text { Lymph nodes } \\
\text { present in PAFP } \\
(\mathrm{n}=76)\end{array}$ & p value \\
\hline $\begin{array}{l}\text { Pathological T stage, n (\%) } \\
\text { pT2 }\end{array}$ & $315(40.8 \%)$ & $32(40.8 \%)$ & 0.518 \\
pT3 & $428(55.4 \%)$ & $39(52.6 \%)$ & \\
pT4 & $30(3.8 \%)$ & $5(6.6 \%)$ & \\
Seminal vesicle invasion, & & & \\
n (\%) \# & $610(82.1 \%)$ & $48(67.6 \%)$ & 0.003 \\
$\begin{array}{l}\text { Negative } \\
\text { Positive }\end{array}$ & $133(17.9 \%)$ & $23(32.4 \%)$ & \\
pN stage, n (\%) & $721(93.3 \%)$ & $62(81.6 \%)$ & $<0.001$ \\
pN- & $52(6.7 \%)$ & $14(18.4 \%)$ & \\
pN+ & & & \\
Surgical Gleason Score, $\mathbf{n}$ & & \\
(\%) & $195(25.2 \%)$ & $17(22.4 \%)$ & 0.030 \\
$\leq 6$ & $432(55.9 \%)$ & $35(46.1 \%)$ & \\
7 & $146(18.9 \%)$ & $24(31.3 \%)$ & \\
$8-10$ & & \\
\hline
\end{tabular}

\# Seminal vesicle invasion: pT2 and pT3 cases.

Of the 76 patients with PAFP lymph nodes, 11 $(1.3 \%)$ had positive prostate cancer metastases. Table 3 presents an analysis of the characteristics of patients having positive PAFP lymph node metastases and those having negative PAFP lymph node metastases. Higher preoperative PSA, Gleason score, and clinical $\mathrm{T}$ stage observations were correlated with the presence of lymph node metastases of prostate cancer.

Table 3. Demographics comparing patients with lymph nodes metastasis present or absent in prostatic anterior fat pad (PAFP).

\begin{tabular}{llll}
\hline Variable & $\begin{array}{l}\text { Lymph nodes metastasis } \\
\text { absent in PAFP }(\mathrm{n}=65)\end{array}$ & $\begin{array}{l}\text { Lymph nodes metastasis } \\
\text { present in PAFP }(\mathrm{n}=11)\end{array}$ & $\begin{array}{l}\mathrm{p} \\
\text { value }\end{array}$ \\
\hline $\begin{array}{l}\text { Age at surgery, } \\
\text { Mean } \pm \text { SD }\end{array}$ & $66.40 \pm 7.38$ & $68.91 \pm 10.53$ & 0.332 \\
$\begin{array}{l}\text { BMI, Mean } \pm \text { SD } \\
\text { Prostate weight, }\end{array}$ & $24.95 \pm 3.23$ & $25.19 \pm 2.70$ & 0.815 \\
Mean \pm SD & $45.62 \pm 23.04$ & $44.18 \pm 13.07$ & 0.841 \\
PSA, $\mathrm{n}(\%)$ & & & \\
$0-10$ & $34(52.3 \%)$ & $2(18.2 \%)$ & 0.006 \\
10-20 & $15(23.1 \%)$ & $1(9.1 \%)$ & \\
$>20$ & $16(24.6 \%)$ & $8(72.7 \%)$ & \\
Preoperative & & & $<0.001$ \\
Gleason Score, $\mathrm{n}$ & & & \\
$\begin{array}{l}\%) \\
\text { 2-6 }\end{array}$ & $34(52.3 \%)$ & $0(0 \%)$ & \\
7 & $19(29.2 \%)$ & $1(9.1 \%)$ & \\
$8-10$ & $12(18.5 \%)$ & $10(90.9 \%)$ & $<0.001$ \\
Clinical T stage, $\mathrm{n}$ & & & \\
$\begin{array}{l}\%) \\
\text { T1abc }\end{array}$ & $19(29.2 \%)$ & & \\
T2/T2a/T2b & $15(23.2 \%)$ & $0(0 \%)$ & \\
T2c & $22(33.8 \%)$ & $2(18.2 \%)$ & \\
T3 & $9(13.8 \%)$ & $8(72.7 \%)$ & \\
\hline
\end{tabular}

Table 4 shows a comparison of the postoperative parameters of patients with and without metastases in PAFP lymph node. Statistically significant differences were observed in patients' pathological T stage $(\mathrm{p}<$ 0.001 ), seminal vesicle invasion, concomitant pelvic lymph node metastases $(p<0.001)$, and surgical Gleason score between the two groups.

Table 4. Surgical and pathologic data comparing patients with lymph nodes metastasis present or absent in prostatic anterior fat pad (PAFP).

\begin{tabular}{|c|c|c|c|}
\hline Variable & $\begin{array}{l}\text { Lymph nodes metastasis } \\
\text { absent in PAFP }(n=65)\end{array}$ & $\begin{array}{l}\text { Lymph nodes metastasis } \\
\text { present in PAFP }(n=11)\end{array}$ & $\begin{array}{l}\mathrm{p} \\
\text { value }\end{array}$ \\
\hline \multicolumn{4}{|c|}{$\begin{array}{l}\text { Pathological T } \\
\text { stage, } \mathbf{n}(\%)\end{array}$} \\
\hline pT2 & $31(47.7 \%)$ & $0(0 \%)$ & $<0.001$ \\
\hline pT3 & $33(50.8 \%)$ & $7(63.6 \%)$ & \\
\hline pT4 & $1(1.5 \%)$ & $4(36.4 \%)$ & \\
\hline \multicolumn{4}{|c|}{$\begin{array}{l}\text { Seminal vesicle } \\
\text { invasion, } \\
\text { n (\%)\# }\end{array}$} \\
\hline Negative & $46(71.9 \%)$ & $2(28.6 \%)$ & 0.020 \\
\hline Positive & $18(28.1 \%)$ & $5(71.4 \%)$ & \\
\hline \multicolumn{4}{|c|}{ pN stage, n (\%) } \\
\hline $\mathrm{pN}-$ & $62(95.4 \%)$ & $0(0 \%)$ & $<0.001$ \\
\hline $\mathrm{pN}+$ & $3(4.6 \%)$ & $11(100 \%)$ & \\
\hline \multicolumn{4}{|c|}{$\begin{array}{l}\text { Surgical } \\
\text { Gleason Score, } n \\
(\%)\end{array}$} \\
\hline$\leq 6$ & $17(26.2 \%)$ & $0(0 \%)$ & 0.005 \\
\hline 7 & $32(49.2 \%)$ & $3(27.3 \%)$ & \\
\hline $8-10$ & $16(24.6 \%)$ & $8(72.7 \%)$ & \\
\hline
\end{tabular}

Five patients $(0.6 \%)$ were upstaged because of the derivation of positive results for metastatic prostate cancer in PAFP lymph nodes but negative findings for PLND. The clinicopathological characteristics of these patients are shown in Table 5 . prostate cancer stages classified as stages IIb and III according to the American Joint Committee on Cancer were upstaged to stage IV after positive metastases in PAFP lymph nodes were found. Patients upstaged to stage IV had high risks preoperatively according to D'Amico classification.

Table 5. The characteristics of the 5 upstaging patients.

\begin{tabular}{|c|c|c|c|c|c|c|c|c|}
\hline Patient & Age & $\begin{array}{l}\text { Pre-op } \\
\text { PSA }\end{array}$ & $\begin{array}{l}\text { Pre-op } \\
\text { Gleason } \\
\text { score }\end{array}$ & $\begin{array}{l}\text { cT } \\
\text { stage }\end{array}$ & $\begin{array}{l}\text { Surgical } \\
\text { Gleason } \\
\text { score }\end{array}$ & $\begin{array}{l}\mathrm{pT} \\
\text { stage }\end{array}$ & $\begin{array}{l}\text { PAFP lymph } \\
\text { node } \\
\text { pos./total }\end{array}$ & $\begin{array}{l}\text { Pelvic lymph } \\
\text { node Pos. } \\
\text { / total }\end{array}$ \\
\hline 1 & 71 & 11.7 & $4+5$ & $\mathrm{~T} 2 \mathrm{~b}$ & $4+5$ & T3b & $1 / 1$ & $0 / 6$ \\
\hline 2 & 45 & 26.0 & $5+3$ & T3a & $5+3$ & $\mathrm{~T} 3 \mathrm{~b}$ & $1 / 1$ & $0 / 9$ \\
\hline 3 & 62 & 112 & $5+4$ & T3a & $4+3$ & $\mathrm{~T} 3 \mathrm{~b}$ & $1 / 1$ & $0 / 13$ \\
\hline 4 & 74 & 25.5 & $4+5$ & T3a & $5+4$ & $\mathrm{~T} 3 \mathrm{~b}$ & $1 / 1$ & $0 / 10$ \\
\hline 5 & 65 & 7.1 & $4+3$ & $\mathrm{~T} 2 \mathrm{c}$ & $3+4$ & T3a & $1 / 1$ & $0 / 13$ \\
\hline
\end{tabular}

\section{Discussion}

To the best of our knowledge, this is the first report showing the prevalence of PAFP lymph nodes with or without prostate cancer involvement among Taiwanese patients. To avoid surgical technique differences, we collected the data of consecutive patients undergoing RALRP performed by a single surgeon who had the largest patient volume. Our data demonstrate that of a total of 849 patients who 
underwent RALRP, 9.0\% harbored PAFP lymph nodes, $1.3 \%$ had metastatic prostate cancer, and $0.6 \%$ were upstaged because the pathological analysis of the PAFP revealed positive metastases in PAFP lymph nodes.

Dissection of the PAFP provides a clearer view of the prostate apex, puboprostatic ligament, dorsal venous complex, and bladder neck. Ahlering et al. [7] initially reported a technique for reducing positive surgical margins during RALRP. They found that dissecting the PAFP off the anterior surface of the prostate and dorsal venous complex could delineate the entire apex of the prostate. This could considerably reduce the positive apical surgical margin rate [7]. They also demonstrated that the PAFP contains lymph nodes and may be upstaged because of positive prostate cancer metastases [8]. Recently, several studies have demonstrated 9\%-17\% of PAFPs to contain lymph nodes (Table 6) $[8-16,18]$.

Table 6. Summary of prostatic anterior fat pad (PAFP) studies.

\begin{tabular}{llllll}
\hline Study & $N$ & $\begin{array}{l}\text { Open } \\
\text { RRP, } n\end{array}$ & $\begin{array}{l}\text { Lymph nodes } \\
\text { present in } \\
\text { PAFP, } n(\%)\end{array}$ & $\begin{array}{l}\text { Lymph nodes } \\
\text { metastasis present in } \\
\text { PAFP lymph nodes, } n \\
(\%)\end{array}$ & $\begin{array}{l}\text { Upstage, } \\
n(\%)\end{array}$ \\
\hline Finley et al. [8] & 204 & 0 & $30(14.7)$ & $4(2)$ & $3(1.47)$ \\
Yuh et al. [10] & 120 & 0 & $20(16.7)$ & $3(2.5)$ & $3(2.5)$ \\
Hansen et al. [18] & 356 & 356 & $19(5.5)$ & $4(1.2)$ & 0 \\
Jeong et al. [9] & 258 & 0 & $30(11.6)$ & $3(1.2)$ & $1(0.39)$ \\
Kim et al. [11] & 4,261 & 124 & $388(11.9)$ & $40(0.94)$ & $27(0.63)$ \\
Aning et al. [12] & 282 & 0 & $49(17)$ & $4(1.4)$ & $3(1.06)$ \\
Ozkan et al. [13] & 100 & 0 & $9(9)$ & 0 & 0 \\
Atmaca et al. [14] & 129 & 0 & $14(10.9)$ & 0 & 0 \\
Ball et al. [15] & 2,413 & 1,266 & $255(10.6)$ & $14(0.6)$ & $63(0.07)$ \\
Kwon et al. [16] & 8,800 & N/A & $206(2.3)$ & $88(0.1)$ & $5(0.6)$ \\
Present study & 849 & 0 & $76(9)$ & $11(1.3)$ & \\
\hline
\end{tabular}

For patients undergoing $\mathrm{RP}$ as the definitive treatment, accurate staging is important to identify patients at risk of disease progression. Previous studies have described that lymphatic drainage of the prostate can be performed through the external iliac, obturator, hypogastric, and presacral lymph nodes $[19,20]$. Manny et al. [17] injected ICG into the prostate before RP and reported that $13 \%$ of patients had detectable fluorescence in the PAFP. They concluded that ICG is highly sensitive but relatively nonspecific for the detection of nodal metastasis. These observations suggest that performing pathological analysis of the PAFP leads to more accurate staging. In our series, PAFP lymph nodes were found in few patients; however, $14.5 \%$ (11 of 76) of the patients harbored malignancy in PAFP lymph nodes compared with $6.8 \%$ (58 of 849 ) of the patients harboring metastases in pelvic lymph nodes. In published series, the rate of metastatic prostate cancer in PAFP lymph nodes ranges from $0.6 \%$ to $2.5 \%$ (Table 6) [8-16, 18]. Two studies have included patients undergoing open radical retropubic prostatectomy (RRP). We determined that the percentage of patients with metastatic PAFP lymph nodes was higher in the RALRP series than in the open RRP series. It is possible that open surgery does not provide as much PAFP tissue as robotic surgery does.

In addition to increasing staging accuracy, the removal of micrometastatic nodes increases the biochemical recurrence (BCR)-free rate [21, 22] and the cancer-specific survival rate in patients treated with PLND [23]. Increased nodal removal during PLND results in more accurate staging and an improved survival rate [24, 25]. Moreover, Altok et al. has shown that prostate cancer was also upstaged during robot-assisted radical prostatectomy (RARP) [26]. In our study, five patients who were upstaged had intermediate or high risks preoperatively according to $\mathrm{D}^{\prime}$ Amico classification. This finding is consistent with those of other series [9, 10]. Moreover, as shown in table 5, no cases with Gleason score 6 had metastatic disease to PAFP. Thus, the beneficial effects in patients with Gleason score $3+3$ need to be further investigated.

Our study demonstrated that only the preoperative $\mathrm{T}$ stage was associated with the presence of PAFP lymph node. However, comparison of patients with metastatic PAFP lymph nodes and those without metastatic PAFP lymph node revealed that higher preoperative PSA, Gleason score, and T stage observations were strongly associated with the presence of lymph node metastases of prostate cancer.

Despite having the strength of consecutive cases and the largest sample size to date among studies of Taiwanese patients, our study is not without limitations. First, we could not conduct long-term follow-up to evaluate the effect of PAFP lymph node removal on BCR rates. Second, because only a few patients were upstaged, we could not compare the categorical data of the two groups: PAFP lymph node $(+)$ /pelvic lymph node $(-)$ and PAFP lymph node $(-) /$ pelvic lymph node $(+)$. Finally, because all patients underwent PAFP removal, we could not determine whether PAFP removal benefits patients. Therefore, additional prospective and categorical analyses with longer follow-up are warranted.

In conclusion, PAFP excision before RP was associated with limited surgical complications and no related morbidity. PAFP excision facilitates achieving a clearer view of the prostate anatomic structure and surgical landmarks. Therefore, we recommend that the PAFP should be removed in all patients during $\mathrm{RP}$, but the routine pathological analysis of the PAFP should only be conducted for those with a high-risk prostate cancer. 


\section{Acknowledgments}

This study was supported by Chung Shan Medical University Hospital (CSH-2013-C-007; CSH-2015-C-018).

\section{Competing Interests}

The authors have declared that no competing interest exists.

\section{References}

[1] Heidenreich A, Bellmunt J, Bolla M, Joniau S, Mason M, Matveev V, et al. EAU guidelines on prostate cancer. Part 1: screening, diagnosis, and treatment of clinically localised disease. Eur Urol 2011; 59: 61-71.

[2] Mohler J, Bahnson RR, Boston B, Busby JE, D'Amico A, Eastham JA, et al. NCCN clinical practice guidelines in oncology: prostate cancer. J Natl Compr Canc Netw 2010; 8: 162-200.

[3] Prendeville S, van der Kwast TH. Lymph node staging in prostate cancer: perspective for the pathologist. J Clin Pathol 2016; 69: 1039-1045.

[4] Messing EM, Manola J, Sarosdy M, Wilding G, Crawford ED, Trump D. Immediate hormonal therapy compared with observation after radical prostatectomy and pelvic lymphadenectomy in men with node-positive prostate cancer. N Engl J Med 1999; 341: 1781-1788.

[5] Schumacher MC, Burkhard FC, Thalmann GN, Fleischmann A, Studer UE. Good outcome for patients with few lymph node metastases after radical retropubic prostatectomy. Eur Urol 2008; 54: 344-352.

[6] Briganti A, Karnes JR, Da Pozzo LF, Cozzarini C, Gallina A, Suardi N, et al. Two positive nodes represent a significant cut-off value for cancer specific survival in patients with node positive prostate cancer. A new proposal based on a two-institution experience on 703 consecutive $\mathrm{N}+$ patients treated with radical prostatectomy, extended pelvic lymph node dissection and adjuvant therapy. Eur Urol 2009; 55: 261-270.

[7] Ahlering TE, Eichel L, Edwards RA, Lee DI, Skarecky DW. Robotic radical prostatectomy: a technique to reduce pT2 positive margins. Urology 2004; 64: 1224-1228.

[8] Finley DS, Deane L, Rodriguez E, Vallone J, Deshmukh S, Skarecky D, et al. Anatomic excision of anterior prostatic fat at radical prostatectomy: implications for pathologic upstaging. Urology 2007; 70: 1000-1003.

[9] Jeong J, Choi EY, Kang DI, Ercolani M, Lee DH, Kim WJ et al. Pathologic implications of prostatic anterior fat pad. Urol Oncol 2013; 31: 63-67.

[10] Yuh B, Wu H, Ruel N, Wilson T. Analysis of regional lymph nodes in periprostatic fat following robot-assisted radical prostatectomy. BJU Int 2012; 109: 603-607.

[11] Kim IY, Modi PK, Sadimin E, Ha YS, Kim JH, Skarecky D, et al. Detailed analysis of patients with metastasis to the prostatic anterior fat pad lymph nodes: a multi-institutional study. J Urol 2013; 190: 527-534.

[12] Aning JJ, Thurairaja R, Gillatt DA, Koupparis AJ, Rowe EW, Oxley J. Pathological analysis of lymph nodes in anterior prostatic fat excised at robot-assisted radical prostatectomy. J Clin Pathol 2014; 67: 787-791.

[13] Ozkan B, Tunc B, Coskuner ER, Saglican Y, Yalcin V. Role of anterior prostatic fat pad dissection for extended lymphadenectomy in prostate cancer: a non-randomized study of 100 patients. Int Urol Nephrol 2015; 47: 959-964.

[14] Atmaca AF, Canda AE, Keske M, Arslan ME, Kamaci D, Alkan E et al. Does anterior prostatic fat tissue removed during robotic radical prostatectomy contain any lymph nodes? Cent European J Urol 2015; 68: 410-414.

[15] Ball MW, Harris KT, Schwen ZR, Mullins JK, Han M, Walsh PC, et al. Pathological analysis of the prostatic anterior fat pad at radical prostatectomy: insights from a prospective series. BJU Int 2017; 119: 444-448.

[16] Kwon YS, Ha YS, Modi PK, Salmasi A, Parihar JS, Patel N, et al. Oncologic outcomes in men with metastasis to the prostatic anterior fat pad lymph nodes: a multi-institution international study. BMC Urol 2015; 15: 79.

[17] Manny TB, Patel M, Hemal AK. Fluorescence-enhanced robotic radical prostatectomy using real-time lymphangiography and tissue marking with percutaneous injection of unconjugated indocyanine green: the initial clinical experience in 50 patients. Eur Urol 2014; 65: 1162-1168.

[18] Hansen J, Budaus L, Spethmann J, Schlomm T, Salomon G, Rink M, et al. Assessment of rates of lymph nodes and lymph node metastases in periprostatic fat pads in a consecutive cohort treated with retropubic radical prostatectomy. Urology 2012; 80: 877-882.

[19] Brossner C, Ringhofer H, Hernady T, Kuber W, Madersbacher S, Pycha A. Lymphatic drainage of prostatic transition and peripheral zones visualized on a three-dimensional workstation. Urology 2001; 57: 389-393.

[20] Mattei A, Fuechsel FG, Bhatta Dhar N, Warncke SH, Thalmann GN, Krause T, et al. The template of the primary lymphatic landing sites of the prostate should be revisited: results of a multimodality mapping study. Eur Urol 2008; 53: 118-125.

[21] Masterson TA, Bianco FJ, Jr., Vickers AJ, DiBlasio CJ, Fearn PA, Rabbani F, et al. The association between total and positive lymph node counts, and disease progression in clinically localized prostate cancer. J Urol 2006; 175: 1320-1324; discussion 1324-1325.
[22] Daneshmand S, Quek ML, Stein JP, Lieskovsky G, Cai J, Pinski J, et al. Prognosis of patients with lymph node positive prostate cancer following radical prostatectomy: long-term results. J Urol 2004; 172: 2252-2255.

[23] Joslyn SA, Konety BR. Impact of extent of lymphadenectomy on survival after radical prostatectomy for prostate cancer. Urology 2006; 68: 121-125.

[24] Briganti A, Chun FK, Salonia A, Gallina A, Zanni G, Scattoni V, et al. Critical assessment of ideal nodal yield at pelvic lymphadenectomy to accurately diagnose prostate cancer nodal metastasis in patients undergoing radical retropubic prostatectomy. Urology 2007; 69: 147-151.

[25] Dorin RP, Lieskovsky G, Fairey AS, Cai J, Daneshmand S. Outcomes after radical prostatectomy for patients with clinical stages T1-T2 prostate cancer with pathologically positive lymph nodes in the prostate-specific antigen era. Urol Oncol 2013; 31: 1441-1447.

[26] Altok M, Babaian K, Achim MF, Achim GC, Troncoso P, Matin SF, et al. Surgeon-led prostate cancer lymph node staging: pathological outcomes stratified by robot-assisted dissection templates and patient selection. BJU Int 2018; in press. 